\title{
Simulation and Research on Automobile Parts of Chassis
}

\author{
Leiming Shi ${ }^{1, a}$, Hongshun Zhang ${ }^{2, b}$, Fuquan Xie ${ }^{1, c}$, Xuewen Cheng ${ }^{3, d}$, \\ Zhihong Wang ${ }^{4, e}$, Chao $\mathrm{Wu}^{1, \mathrm{f}}$, Yanxia Du ${ }^{1, \mathrm{~g}}$ and Shunli Feng ${ }^{1, \mathrm{~h}}$ \\ ${ }^{1}$ Henan Vocational and Technical College of Communications, Zhengzhou 450000, China \\ ${ }^{2}$ The Yellow River Institute of Communications, Jiaozuo 454950, China \\ ${ }^{3}$ Dongfeng Motor Corporation R \& D Center 442000, China \\ ${ }^{4}$ Chongqing Jiaotong University, Ghongqing 400074,China

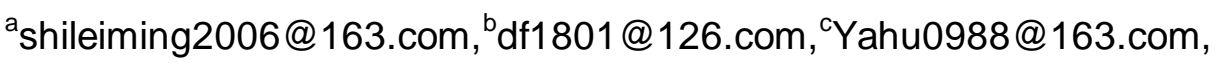

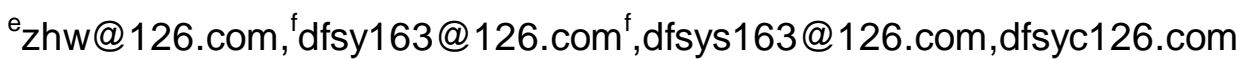

\section{Keywords: Automobile parts; Simulation; Finite element; Orthogonal experiment}

\begin{abstract}
The purpose of this project was to effectively avoid the defects in the production of the Dongfeng Automobile chassis floor. The research scope was the technological process of the rear floor parts of Dongfeng Automobile. The forming process of the rear floor parts of the Dongfeng Automobile model was analyzed, and the whole process numerical simulation model of the rear floor part was established by using the AutoForm software. The influence of blank holding force, convex concave clearance and drawing speed on the thinning rate and secondary strain of forming parts was analyzed by orthogonal experiment design. The 3 factors, blank holder force, convex concave clearance and drawing speed were analyzed. The optimal combination of edge pressure, convex concave gap and drawing speed were determined by multi-objective optimization. The best parameter combination results: BHF was $1273 \mathrm{kN} 1.10 \mathrm{t} \mathrm{mm}$, the gap between punch and die, drawing speed was $15 \mathrm{~mm} / \mathrm{s}$, the thickness of the parts could meet the requirements of guidance for automotive production, but in mass production, also need to consider in the process of the specific choice of the plate material, the internal organization so, these would affect the process stability. In conclusion, the whole process simulation and orthogonal experiment design could effectively avoid forming defects and determine the forming parameters, and provide guidance for practical production in theory, and provide technical support for the optimization of Dongfeng vehicle floor.
\end{abstract}

\section{Introduction}

The traditional new mold development depended on the designer's experience. It took a lot of time in the process of mold debugging. On the one hand, it would prolong the development cycle of the mold, On the other hand, increase the mold development cost $[1,2]$.With the rapid development of computer technology, the numerical simulation technology was widely used in the development of automobile die

$[3,4]$.The numerical simulation could be used to predict the defects in the forming accurately, thus avoiding the possible defects before the die input and shortening the development cycle of the die. [5]

The commonly used analysis software for sheet metal forming was AutoForm in Switzerland, Dynaform in America, PAM-STAMP in France, JSTAMP in Japan, SheetForm and Vform in China and so on. The drawbeads of drawing forming were optimized with Dy-naform and orthogonal test by Wang Lieliang [6], etc. Zhang Yuping $[7,8]$ and so on utilized AutoForm to analyze the interior plate of the automobile, and studied the influence of the related forming parameters on the drawing, and optimized it.

The author used AutoForm to simulate the whole process of Dongfeng Automobile chassis floor parts from drawing process, trimming process and flanging process, and comprehensively analyzed the possible problems in each process, avoiding the influence of process considerations on mold 
development cycle and manufacturing cost. The orthogonal experiment and multi-objective optimization method were used to optimize the drawing process parameters, and the optimized parameters were tested.

\section{Process Analysis}

In view of the chassis parts of Dongfeng Automobile, the whole process simulation was divided into drawing, cutting and flanging through the analysis of the whole process. The numerical simulation focused on the formability of the parts in the drawing stage, the forming defects and the requirements of the product. In the cutting stage, the effect on the subsequent flanging was mainly considered. They were considered in the flanging process that whether the flanging was feasible, whether there were defects or not and whether the height of the flanging was in conformity with the requirements.

In the design of practical parts, the process arrangement was different from the whole process simulation, and the feasibility, the easy operation and the economic benefit should be considered at the same time. For example, when arranging the trimming process, it was different from numerical simulation. In numerical simulation, the trimming could be completed at one time. According to the actual conditions of the parts, the location of the trimming block, the slide of the waste, and so on, the trimming was usually completed in more than two processes. Although the process arrangement of the whole process simulation might be different from the actual working procedure, the whole process simulation was of great significance in the development of the mould.

\section{The Establishment of Full Process Simulation Model}

The material for the chassis floor was BLC, with a thickness of $0.8 \mathrm{~mm}$. According to the characteristics of floor part, Process replenish surface and binder surface were increased. Among them, figure 1a was a drawing process, including gravity simulation of billet, closed edge of blank holder and closed drawing of die and punch. Figure $1 \mathrm{~b}$ was the cutting process, which was removed from the non product section around the part. The edge contour was calculated from the flanged parts. Figure 1c was the flanging process, including the upward flanging and the down flanging. The parts were fixed under the combined action of the feeder and the press, and the upper flanging die would turn the edges of the parts downward, and the lower flanging die would turn the parts upwards.

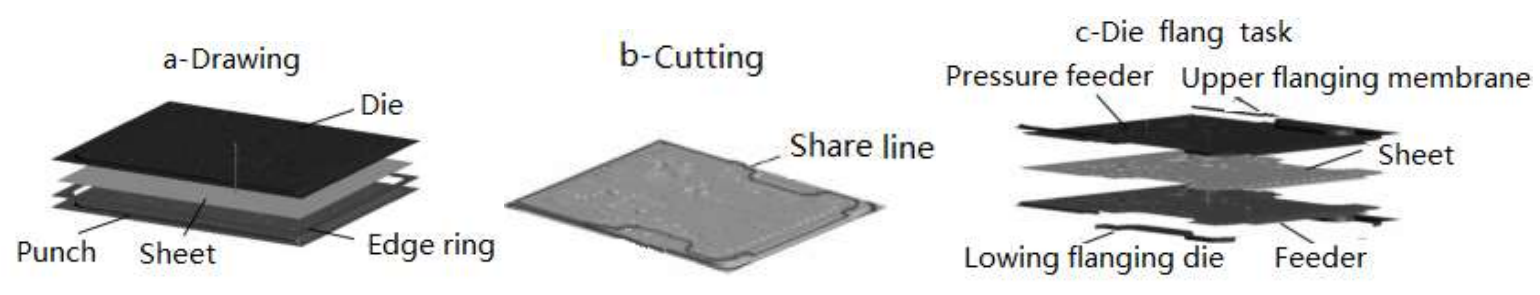

Figure 1. Full cycle simulation of rear floor part in AutoForm

\section{Process Optimization}

The quality of the drawing parts of the automobile panel would directly affect the quality of the following parts and the final parts. The orthogonal test design was used to optimize the related parameters of the drawing process and determined the optimal combination of drawing process parameters, which would guide the actual production. Orthogonal test design was able to select representative combinations of parameters from comprehensive tests when researching multiple factors and levels. It had the characteristics of uniform dispersion and comprehensive. It was widely applied in experimental design [9].

Orthogonal Experimental Design. The Considering the 3 factors of blank holder force, convex concave clearance and drawing speed in the orthogonal test, the range of factors was determined 
according to the actual situation and single factor experiment $[10]$.The influence factors in orthogonal experimental design were set as blank holder force $\mathrm{Fb}$ (factor $\mathrm{A}$ ), concavo concave gap d (factor $\mathrm{B}$ ), drawing speed $\mathrm{v}$ (factor $\mathrm{C}$ ), each factor contained 3 levels, and 3 factor and 3 level orthogonal table were established. Table 1 was an orthogonal test factor level table, in which $t$ was the thickness of the sheet.

Table 1 Level and factor of orthogonal test

\begin{tabular}{|cccc|}
\hline level & $\begin{array}{c}\text { FactorA } \\
\mathrm{Fb} / \mathrm{kN}\end{array}$ & $\begin{array}{c}\text { FactorB } \\
\mathrm{d} / \mathrm{mm}\end{array}$ & $\begin{array}{c}\text { FactorC } \\
\mathrm{v}\left(/ \mathrm{mm} \cdot \mathrm{s}^{-1}\right)\end{array}$ \\
\hline 1 & 1273 & $1.05 \mathrm{t}$ & 10 \\
2 & 1470 & $1.10 \mathrm{t}$ & 15 \\
3 & 1665 & $1.15 \mathrm{t}$ & 20 \\
\hline
\end{tabular}

Experimental Result. The quality of the drawing part was determined by many factors. The author investigated the maximum thinning rate and the minimum substrain after the forming of the parts. For the ordinary steel plate, the product surface thinning rate of the drawing parts should be less than or equal to $25 \%$, and the reduction rate of the process compensation surface should not exceed $30 \%$

$[11,12]$.According to the requirement of the car manufacturer, the change of the main strain and the secondary strain should be uniform, and more than -0.05 . The main strain in the sheet metal forming was generally greater than 0 , so the minimum strain was considered in the corresponding variable analysis.

According to the orthogonal experimental design method, 9 experimental groups could be obtained, respectively, according to the configuration parameters, and the simulation calculation was carried out. Table 2 was the result of orthogonal test.

Table 2 Results of orthogonal experiment

\begin{tabular}{|cccccc|}
\hline & & & \multicolumn{2}{c|}{$\begin{array}{l}\text { aximum } \\
\text { reduction rate } / \%\end{array}$} & $\begin{array}{l}\text { Minimum } \\
\text { sub strain }\end{array}$ \\
\hline 1 & 1 & 1 & 1 & 17.66 & -0.0497 \\
2 & 1 & 2 & 2 & 17.14 & -0.0461 \\
3 & 1 & 3 & 3 & 16.26 & -0.0558 \\
4 & 2 & 1 & 2 & 17.88 & -0.0529 \\
5 & 2 & 2 & 3 & 18.51 & -0.0382 \\
6 & 2 & 3 & 1 & 17.47 & -0.0501 \\
7 & 3 & 1 & 3 & 18.97 & -0.0494 \\
8 & 3 & 2 & 1 & 19.37 & -0.0386 \\
9 & 3 & 3 & 2 & 19.93 & -0.0364 \\
\hline
\end{tabular}

Extreme Analysis. The influence of blank holder force, convex concave clearance and drawing speed on the maximum thinning rate and minimum secondary strain of the parts was compared. The results of orthogonal test were analyzed by range analysis. Table 3 was the result of the extreme analysis. In the extreme analysis, $\mathrm{R}$ was the fluctuation index of each parameter, and Rank was the order of influence on the test factors. The extreme difference analysis reflected the effect of the change of the level of the test factor on the result. The greater the value of $\mathrm{R}$, the greater the influence of the factor to the result it showed.

From table 3, it could be found that the most influential factor for the maximum thinning rate was the blank holder force in 3 factors such as the pressing force, the gap between the convex and the concave, and the drawing speed. 
The influence of the maximum thinning rate from large to small was the edge force, the concave gap and the drawing speed. The influence of the blank holder force and the gap between the convex and concave on the minimum strain was greater than the effect of the drawing speed on the minimum strain.

Table 3 Results of range analysis

\begin{tabular}{|ccccc|}
\hline Factor & \multicolumn{2}{c}{ Maximum thinning rate/\% } & \multicolumn{2}{c|}{ Minimum sub strain } \\
& $\mathrm{R}$ & Rank & R & Rank \\
\hline A & 2.38 & 1 & 0.010 & 1 \\
B & 0.45 & 2 & 0.010 & 1 \\
C & 0.41 & 3 & 0.003 & 2 \\
\hline
\end{tabular}

Multiobjective optimization. In order to find the maximum thinning rate and minimum sub strain and achieve the optimal value simultaneously, multi-objective optimization was applied to determine the optimal parameter combination of blank holder force, convex concave clearance and drawing speed. A multi-objective optimization goal was that the maximum thinning rate was below $25 \%$ and the minimum strain was larger than -0.05 .

Table 4 Results of multi-objective optimization

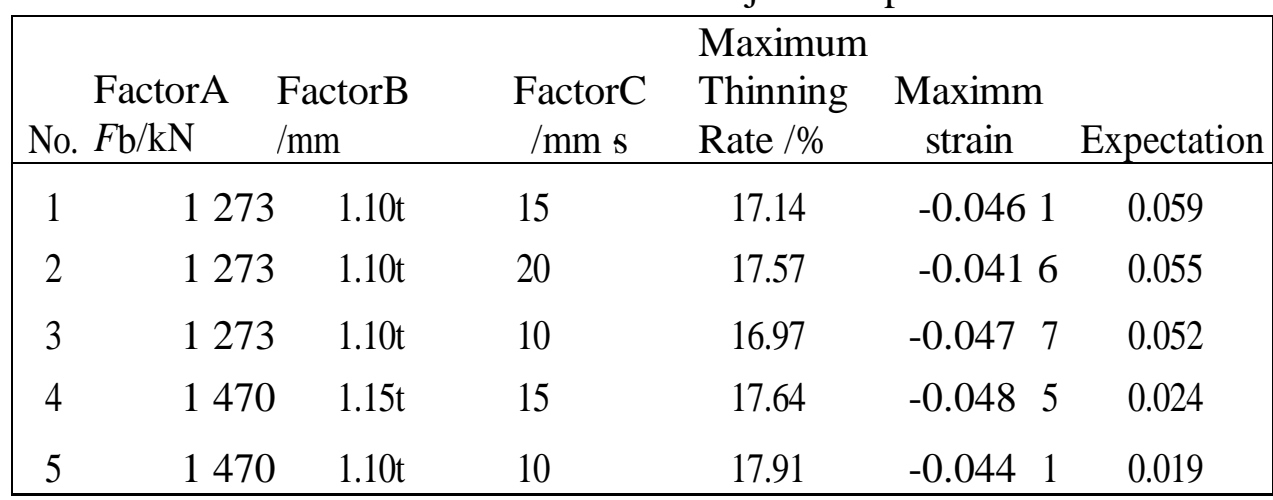

a-Drawing part

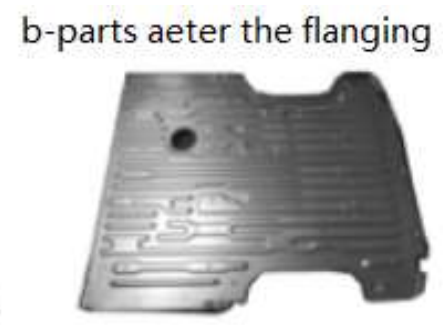

Figure.2 Forming part in experimen

Table 4 was a multi-objective optimization result calculated by using the experimental design software Design-Expert [13]. Table 4 listed the results in which some of the expected values were maximum and meet the multiobjective requirements, of which the first groups had the maximum expected value, that was, the selection of the 1 groups as the optimal parameter combination.

\section{Experimental Verification}

The optimized parameters were used to design the die for experimental verification, and Figure 2 was the part of the experiment. The drawing $2 \mathrm{a}$ was the drawing part, and the figure $2 \mathrm{~b}$ was the part after the final flanging. By observing the non forming defects of the parts, the thickness of the parts was measured by the sharp corner micrometer, and the thinning rate is within the qualified range. 


\section{Conclusion}

The whole process simulation considers the interaction between different processes. It was of great practical value to simulate the whole forming process and avoid defects effectively. The most influential factor for the maximum thinning rate was the blank holder force. The most influential factors for the minimum substrain were the blank holder force and the convex concave gap. Through orthogonal test, the optimal combination of parameters was obtained: the edge force was $1273 \mathrm{kN}$, the gap between the convex and concave die was $1.10 \mathrm{t} \mathrm{mm}$, and the drawing speed was $15 \mathrm{~mm} / \mathrm{s}$.It was verified by experiments that the parts had no defects and the thickness of the parts met the requirements.

Funded projects of the Dongfeng national scientific research fund(50975260)

\section{References}

[1] Wang and L.Lang: Sheet metal forming CAE design and application (Beihang University press, China 2013).p.25.In Chinese.

[2] H.Y.Gong: CAE practical course for sheet metal stamping (chemical industry press, China 2010).p.20.In Chinese.

[3] Y.L.Yang. Analysis of stamping process for automobile panel based on CAE technology (MS. ,Qingdao Technological University, China 2013), p.20. In Chinese.

[4] X.C.Zhuang, Y.Z. Wang and X.H. Zhang: Forging technology,Vol.40(2015)No.8,p.9. In Chinese.

[5] Z.Wang, Y.M Xie and J.Hu: China Mechanical Engineering,Vol.24(2013)No.22,p.3075. In Chinese.

[6] L.L.Wang, Y.P.Zheng and G.Yan: Thermal processing technology,Vol.30(2014)No.5,p.142.In Chinese.

[7] Y.P.Zhang: Weapons materials science and engineering, Vol.36(2013)No.3,p.96. In Chinese.

[8] J.Y.Yang and M.Q.Yuan: modern machinery, Vol.52(2014)No.1,p.96. In Chinese.

[9] L.Chen, P. Huang and J. Wang: Journal of Plasticity Engineering,Vol.25(2012)No.4,p.1.In Chinese.

[10] Y.Y.Zheng, X.M.Liu, Y. W. Zhao and R.H. Liu :Journal of Jilin Institute of Chemical Technology, Vol.33(2016)No.5,p.46. In Chinese.

[11]H.Zheng: Industrial and engineering technology,Vol.30(2015)No.11,p.219. In Chinese.

[12] C.Zhibo. Study on the optimization of stretch plate drawing process before side enclosure (MS. ,Wuhan University of science and technology, China 2011), p.22. In Chinese.

[13] J.Liu, H.Zhang, Y.Shi: Chinese Journal of mechanical engineering, Vol.47(2011)No.16,p.52.In Chinese 